\title{
Loss of TIPE2 Has Opposing Effects on the Pathogenesis of Autoimmune Diseases
}

\section{OPEN ACCESS}

Edited by:

Gang Wang,

Fourth Military Medical

University, China

Reviewed by:

Kevin M. Nickerson,

University of Pittsburgh, United States

Honglin Wang,

Shanghai Jiao Tong University, China

*Correspondence:

Ting Wang

wt-ting@163.com

Qingguo Ruan

ruanqg222@hotmail.com

${ }^{\dagger}$ These authors have contributed equally to this work

Specialty section:

This article was submitted to Autoimmune and Autoinflammatory Disorders,

a section of the journal

Frontiers in Immunology

Received: 11 April 2019 Accepted: 10 September 2019 Published: 24 September 2019

Citation:

Liu R, He X, Geng W, Wang T and Ruan Q (2019) Loss of TIPE2 Has Opposing Effects on the Pathogenesis

of Autoimmune Diseases.

Front. Immunol. 10:2284.

doi: 10.3389/fimmu.2019.02284

\author{
Ruiling Liu ${ }^{1,2 \dagger}$, Xiaozhen $\mathrm{He}^{3 \dagger}$, Wenwen Geng ${ }^{3}$, Ting Wang ${ }^{4 *}$ and Qingguo Ruan ${ }^{1,4 *}$ \\ ${ }^{1}$ Center for Antibody Drug, Institute of Biomedicine and Biotechnology, Shenzhen Institutes of Advanced Technology, \\ Chinese Academy of Sciences, Shenzhen, China, ${ }^{2}$ University of Chinese Academy of Sciences, Beijing, China, ${ }^{3}$ School of \\ Medicine and Life Sciences, University of Jinan, Shandong Academy of Medical Sciences, Jinan, China, ${ }^{4}$ State Key \\ Laboratory Cultivation Base, Shandong Provincial Key Laboratory of Ophthalmology, Shandong Eye Institute, Shandong First \\ Medical University \& Shandong Academy of Medical Sciences, Qingdao, China
}

Autoimmune diseases are a physiological state wherein immune responses are directed against and damage the body's own tissues. Cytokines secreted by infiltrated inflammatory cells contribute to the pathogenesis of autoimmune diseases. TIPE2, one of the four family members of Tumor necrosis factor- $\alpha$ induced protein-8 (TNFAIP8), is a negative regulator of innate and adaptive immunity and plays essential roles in the maintenance of immune tolerance. However, studies on the role of TIPE2 during the development of autoimmune diseases have generated contradictory results. In the current study, we sought to determine the role of TIPE2 during the development of IMQ-induced psoriasis and Experimental Autoimmune Uveitis (EAU) in mice. Our study revealed that, while TIPE2-deficiency alleviates psoriasis, it exacerbates the development of EAU. Further studies demonstrated that, although TIPE2-deficient T cells produced more IL-17A, they do not migrate efficiently to the local inflammatory site, i.e., the skin. This in turn led to the decreased IL-17A production in the skin and consequently reduced the severity of psoriasis in TIPE2-deficient mice. However, although TIPE2-deficient T cells still produced more IL-17A in EAU model, they migrate into the inflamed eye as efficient as TIPE2-sufficient T cells, and consequently exacerbates the development of EAU in TIPE2-deficient mice. Taken together, these results indicate that TIPE2 may either promote or suppress autoimmunity depending on the specific inflammatory microenvironment in different types of autoimmune diseases.

Keywords: TIPE2, psoriasis, IL-17A, migration, EAU

\section{INTRODUCTION}

Autoimmune disease occurs when healthy body tissues were mistakenly attacked and destroyed by body's own immune system. More than 80 types of different autoimmune diseases have been reported, including psoriasis, Experimental Autoimmune Uveitis (EAU), type 1 diabetes, Experimental Autoimmune Encephalomyelitis (EAE), and Rheumatoid Arthritis (RA). Besides genetic and environmental factors, immunological factor often plays important roles during the pathogenesis of autoimmune disease which triggers the initiation of the disease as well as maintaining the disease state $(1,2)$. T cells, especially the IL-17A-producing Th17 cells, have been shown to play a dominant role during the pathogenesis of multiple autoimmune diseases including psoriasis and EAU (3-8). Following priming, Th17 cells migrate to local inflammatory site which 
was mediated by tissue selective integrins and chemokine receptors (9). While IL-17A knockout mice develop significantly less severe psoriasis and EAU $(10,11)$, treatment with anti-IL17A antibody markedly reduced inflammation in both psoriatic and EAU mice (12-14).

Tumor necrosis factor- $\alpha$ induced protein-8-like 2 (TNFAIP8L2 or TIPE2) is one member of the TNFAIP8 family. Current study suggests that TIPE2 is a negative regulator of innate and adaptive immune responses (15). TIPE2 is preferentially expressed by immune cells and TIPE2-deficient cells are hyper-responsive to Toll-like receptor (TLR) and $\mathrm{T}$ cell receptor (TCR) activation. Further study revealed that TIPE2 may inhibit the activation of NF- $\kappa \mathrm{B}$ in T cells and macrophages (15). Since TIPE2 is a negative regulator of immune response, it may play important roles during the pathogenesis of autoimmune disease. In fact, TIPE2 down-regulation was found in the peripheral blood mononuclear cells from patients with Systemic Lupus Erythematosus (SLE) (16). In 2016, Xu et al. reported that TIPE2 alleviates experimental SLE through the induction of M2 macrophage (17). In addition, decreased TIPE2 expression was also found to be correlated with the occurrence and development of RA (18). However, researchers have also found that TIPE2 promotes the development of colitis (19). Recently, Fayngerts et al. reported that TIPE2-deficient leukocytes were defective in polarization and chemotaxis, and consequently TIPE2-deficient mice were resistant to EAE which was mediated by leukocyte (20). Thus, the role of TIPE2 during the development of autoimmune diseases remains elusive.

In the current study, we sought to determine the role of TIPE2 during the development of IMQ-induced psoriasis and EAU in mice. Our study revealed that, although TIPE2 exacerbates the development of psoriasis through promoting the directional migration of $\mathrm{T}$ cells to the site of inflammation, it alleviates EAU through the suppression of IL-17A production by T cells.

\section{MATERIALS AND METHODS}

\section{Animals}

Four to six week-old wild-type and TIPE2-deficient mice in the C57BL/6 background were used in the experiments and kept under pathogen-free conditions at the animal core facility of the Shenzhen Institutes of Advanced Technology, Chinese Academy of Sciences. All efforts were made to minimize the number of mice used and to less animal distress, pain, and injury. Carbon dioxide $\left(\mathrm{CO}_{2}\right)$ was used to euthanize mice. All procedures were preapproved by the Animal Care and Use Committee of Shenzhen Institutes of Advanced Technology, Chinese Academy of Sciences.

\section{Induction and Clinical Evaluation of Psoriasis}

Commercially available IMQ cream (Aldara, Inova pharmaceuticals, USA) was smeared on the shaved back of wild-type and TIPE2-deficient mice in the C57BL/6 background at 4-6 weeks of age as previously reported (21). Alternatively, $\mathrm{CD}^{+} \mathrm{T}$ cells were isolated from wild-type and TIPE2-deficient mice and adoptively transferred into $\mathrm{Rag}^{-/-}$mice $(10 \times$
$10^{6} /$ mouse). IMQ cream was then used to induce psoriasis as mentioned above. The severity of inflammation of the back skin was evaluated according to the clinical psoriasis area and severity index (PASI) $(22,23)$. In order to obtain histological profiles of the back skin, skin sections were first fixed in $10 \%$ formalin, and then embedded in paraffin, sectioned, and stained with hematoxylin/eosin. Skin sections were finally examined by microscopy.

\section{Induction and Clinical Evaluation of EAU}

EAU was induced by active immunization as previously described (24). Briefly, mice were immunized with IRBP1$20(4 \mathrm{mg} / \mathrm{ml}$, GPTHLFQPSLVLDMAKVLLD, purchased from China Peptides) emulsified 1:1 in complete Freund's adjuvant (Chondrex, USA) with an additional $100 \mu$ l mycobacterium tuberculosis H37R ( $2.5 \mathrm{mg} / \mathrm{ml}$, BD biosciences, USA) at the base of the tail and $50 \mu \mathrm{l}$ in each thigh (400 $\mu \mathrm{g}$ peptide per mouse). An additional $200 \mu \mathrm{g}$ bordetella pertussis toxin (Abcam, USA) was intravenously injected immediately after peptide injection. Eyes were harvested 21 days after immunization and stained with hematoxylin/eosin, and the severity of EAU was evaluated on a scale of 0-4 using previously published criteria (25).

\section{RNA Isolation and RT-PCR}

To prepare total skin cells, the back skin of the mice were collected and washed with cold washing buffer (PBS $+2 \%$ FBS), then cut into small pieces and incubated in DMEM supplemented with $0.5 \mathrm{mg} / \mathrm{ml}$ collagenase D (Sigma, USA), 0.02 $\mathrm{mg} / \mathrm{ml} \mathrm{DNase}$ (Roche, USA), and $0.1 \mathrm{mg} / \mathrm{ml}$ Dispase (Sigma, USA) for $20 \mathrm{~min}$ at $37^{\circ} \mathrm{C}$ with gentle shaking. Supernatant was collected and filtered through a 70- $\mu \mathrm{m}$ strainer (BD Biosciences, USA) to obtain single-cell suspension. Total RNA was isolated using TRIzol reagent following manufacturer's instructions (Life Technologies, USA). RNA samples were reversely transcribed using the primescript reverse transcription kit (Takara, JPN). The expression of chemokines was determined by quantitative RTPCR using specific primers and Applied Biosystems 7500 system. When determining the relative level of gene expression, GAPDH was used as the internal control. The primers for the detection of mouse chemokines and GAPDH were synthesized as previously described $(26,27)$.

\section{ELISA Assay}

For cytokine assays, purified $\mathrm{CD}^{+} \mathrm{T}$ cells from spleen and total cells from inguinal lymph node (ILN), cervical lymph node $(\mathrm{CLN})$, spleen or eye were cultured at $1 \times 10^{6}$ cells/well in $100 \mu \mathrm{l}$ of complete DMEM culture medium (Corning, USA) in the presence or absence of anti-CD3 (ebioscience, USA) and/or anti-CD28 (ebioscience, USA). The concentrations of anti-CD3 and anti-CD28 were indicated within the figure or figure legend. Culture supernatants were collected after $48 \mathrm{~h}$; For the preparation tissue extract, total cells from the back skin of the mice were homogenized in 1\% chaps (Sigma, USA) supplemented with complete protease inhibitor mixture (Roche, USA). The concentration of IL17A in the cell culture supernatant and tissue extract was determined by quantitative enzyme-linked 
immunosorbent assay (ELISA) per manufacturer's instructions (eBioscience, USA).

\section{Antibodies and Flow Cytometry}

Flow cytometric analyses were performed on freshly isolated cells from skin, blood, ILN, CLN, and eye. Cells were labeled with a combination of the following fluorescence-conjugated mouse mAbs: PE-anti-CD4, APC-anti-CD8, PerCP-Cy5.5-anti-CD3, APC-anti-CD183(CXCR3), APC-anti-CD184 (CXCR4), PEanti-CD194 (CCR4), APC-anti-CD195(CCR5), PerCP/Cy5.5anti-CD196 (CCR6), APC-anti-CD197(CCR7), and FITC-antiCD199 (CCR9). All antibodies were purchased from BioLegend. For the intracellular staining of IL-17A, cells from the skin or eye were stimulated with PMA + ionomycin (eBioscience, USA) in the presence of GolgoStop (1:1,500 dilution, BD, USA) for $6 \mathrm{~h}$. Cells were then collected and first stained with anti-CD3. After fixation and permeabilization, cells were then stained with anti-IL-17A (BioLegend, USA) per manufacturer's instructions (Invitrogen, USA). For the intracellular staining of phosphoI $\mathrm{B} \alpha$, cells from the skin or eye were first stained with anti-CD3. After fixation and permeabilization, cells were then stained with purified anti-phospho-IкB $\alpha$ (Ser32/36) antibody (CST, USA), followed by staining with DyLight ${ }^{\mathrm{TM}} 488$-conjugated goat antimouse IgG (BioLegend, USA) per manufacturer's instructions (Biolgend, USA). Stained cells were then examined on CytoFLEX flow cytometry system (Beckman Coulter Inc., USA).

\section{Transwell Migration Assay}

Lymphocytes were isolated from blood using mouse peripheral blood lymphocyte isolation kit (Tian Jin Hao Yang Biological Manufacture CO., LTD, China). Total T cells were isolated from blood lymphocyte and ILN using EasySep ${ }^{\mathrm{TM}}$ Mouse T Cell Isolation Kit (Stemcell, USA) and "rest" in RPMI1640 culture medium for $1 \mathrm{~h}$. Migration assays were then performed using Transwells. Briefly, cells were placed on the upper layer of a cell permeable membrane of 24 -well transwell plate $(5 \mu \mathrm{m}$ pore size, Corning, USA $)$ at $5 \times 10^{4} /$ well. IP10 $(10 \mathrm{ng} / \mathrm{ml}$, Biolegend, USA), CCL19 (10 ng/ml, Biolegend, USA), or PBS (control group) was placed below the cell permeable membrane. Following an incubation period of $3 \mathrm{~h}$, the cells that have migrated through the membrane are counted by TC10 automated cell counter (Bio-Rad, USA). The chemotaxis index was calculated by dividing the number of cells that migrated in response to chemoattractant with the number of cells that migrated in the control group.

\section{Confocal Microscopy Analysis}

Total $\mathrm{T}$ cells were isolated from the ILN using EasySep ${ }^{\mathrm{TM}}$ Mouse T Cell Isolation Kit (Stemcell, USA). After resting in RPMI1640 culture medium for $1 \mathrm{~h}$, cells were subjected to pointsource stimulation with IP10 (Biologend, USA) at $1 \mu \mathrm{g} / \mathrm{ml}$ for $3 \mathrm{~min}$ at $37^{\circ} \mathrm{C}$. Cells were then fixed with $4 \%$ paraformaldehyde for $15 \mathrm{~min}$ at room temperature, permeabilized with $0.1 \%$ TritonX-100 in PBS for $10 \mathrm{~min}$ and blocked with 5\% normal rat serum plus $3 \%$ BSA for $1 \mathrm{~h}$ at room temperature. After fixation and permeabilization, cells were incubated overnight with a 1:100 dilution of Phospho-AKT (T308) antibody (Cell
Signaling Technology, USA) and a 1:1,000 dilution of PhalloidiniFluor647 (CST, USA). Cells were then washed three times and incubated for $30 \mathrm{~min}$ with 1:1,000 diluted DyLight ${ }^{\mathrm{TM}} 488$ Donkey anti-rabbit IgG antibody (Biolegend, USA). Stained cells were then washed, dried and covered with ProLong Gold with DAPI (Invitrogen, USA). Images were acquired using a Leica TCS SP5 confocal microscope and analyzed using ImageJ software.

\section{Statistical Analysis}

The significance of the difference in disease severity was determined by Mann-Whitney $U$-test. The skin thickness, mean florescence intensity (MFI), level of cytokines and percentage of cells were analyzed by Student's $t$-test.

\section{RESULTS}

\section{TIPE2-Deficiency Alleviates Psoriasis but Promotes the Development of EAU}

IMQ is a ligand for TLR7/8 that when applied topically to the skin, induces psoriasis-like inflammation in susceptible mice including $\mathrm{BABL} / \mathrm{c}$ and $\mathrm{C} 57 \mathrm{BL} / 6$. The IMQ-psoriasis closely resembles human psoriasis lesions with respect to phenotypic and histological characteristics. EAU is the animal model of human uveitis that most closely resembles sympathetic ophthalmia. It is the most widely used and well-studied uveitis model. In order to determine the roles of TIPE2 in the pathogenesis of different types of autoimmune diseases, we established IMQ-induced psoriasis model and EAU model in wild-type and TIPE2-deficient mice in the C57BL/ 6 background. As shown in Figure 1A, IMQ-induced skin inflammation in TIPE2-deficient mice resulted in lower scores for erythema and scaling at the peak-stage of the disease. The difference is small but significant. Although IMQ-induced psoriasis is a $\mathrm{T}$ cell-dependent disease, other hematopoietic cell types may also contribute to the pathogenesis. In order to directly test the T cell-specific function of TIPE2 in psoriasis, we studied the IMQ-induced psoriasis in $\mathrm{Ragl}^{-/-}$mice that had received WT or TIPE2-deficient T cells. We found that mice received TIPE2-deficient $\mathrm{T}$ cells developed less severe symptoms than those reconstituted with WT T cells (Figure 1B). Consistent with these clinical findings, H\&E-stained sections of skin from TIPE2-deficient mice demonstrated decreased epidermal thickening by Figures 1C,D. In contrast to the phenotype difference displayed in IMQ-induced psoriasis model, TIPE2deficient mice exhibited more severe retinal edema and structural distortion in the EAU model (Figure 1E). When pathological changes in the retina were evaluated according to the scoring criteria previously reported, WT mice had a mean score of 0.8 , whereas that number for TIPE2-deficient mice is 1.8 (Figure 1F). Similar phenotypical difference was also detected when EAU was induced in mice adoptively transferred with T cells from either WT or TIPE2-deficient mice (Figure 1G). Since both IMQ-induced psoriasis and EAU are T-cell mediated autoimmune disease animal model and our study has also established that TIPE2 in T cells regulates the pathogenesis of both psoriasis and EAU, in this study we focused on the roles 
A

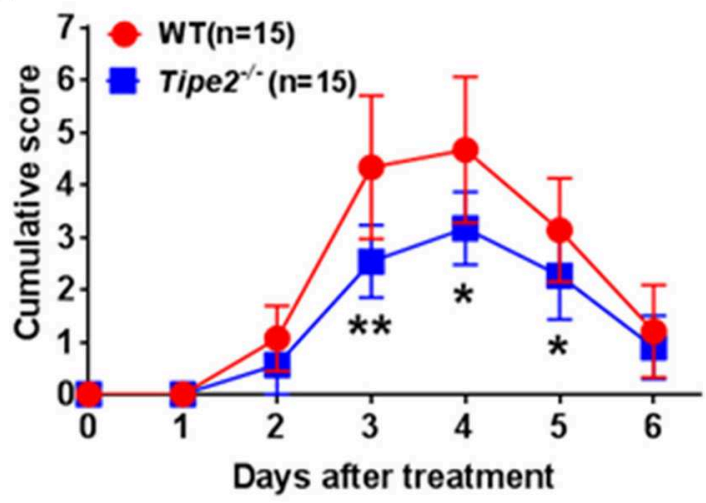

C
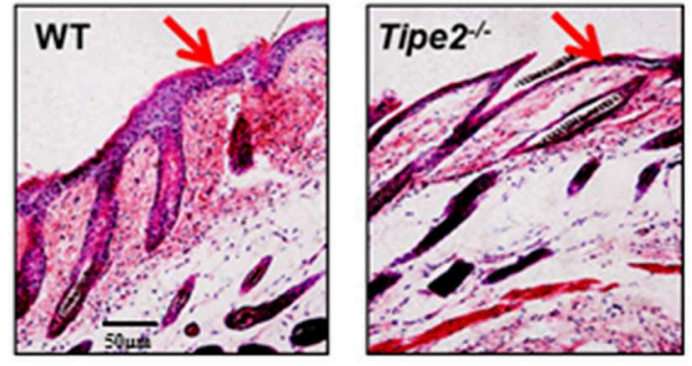

B

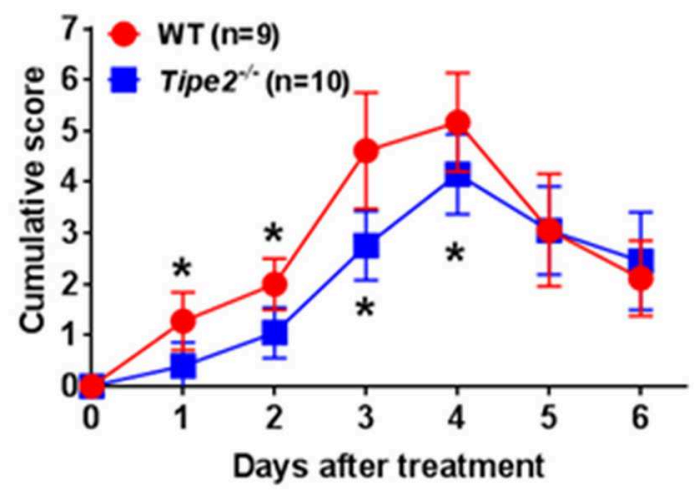

D

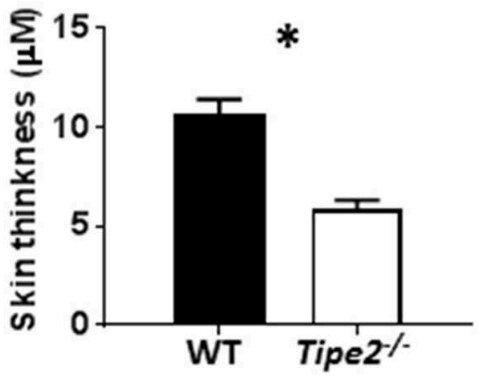

E
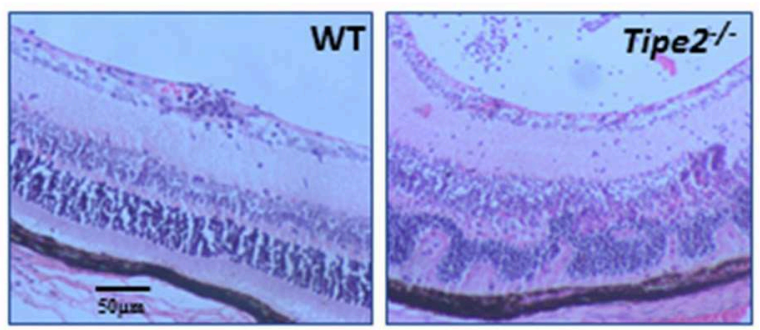

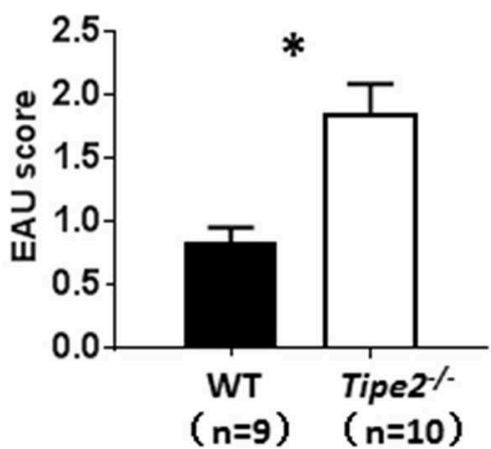

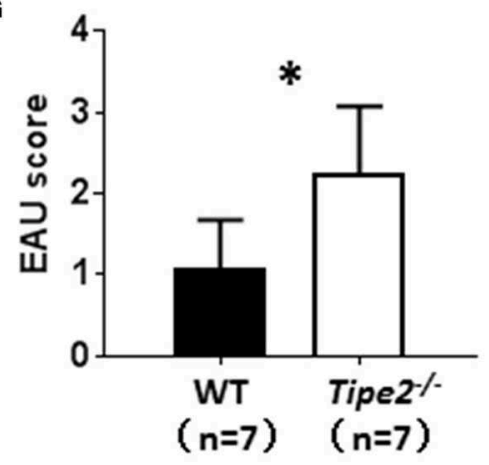

FIGURE 1 | TIPE2-deficiency alleviates psoriasis but promotes the development of EAU. (A) WT $(n=15)$ and TIPE2-deficient $(n=15)$ mice in the C57BL/6 background were treated with IMQ cream on the shaved back skin as mentioned in the Materials and Methods. Mice were monitored for the development of erythema and scaling on the back skin. The cumulative score (erythema plus scaling) is depicted. Data were combined from two separate experiments. (B) Total T cells were isolated from wild-type and TIPE2-deficient mice and adoptively transferred to Rag1-/- mice (10 × $\left.10^{6} / \mathrm{mouse}\right)$. IMQ cream was used to induce psoriasis as mentioned in the Materials and Methods. The cumulative score (erythema plus scaling) was calculated as mentioned in (A). Data were 
FIGURE 1 | combined from two separate experiments. (C) Mice from (A) were killed 6 days after the first IMQ treatment and H\&E staining of the back skin of mice was performed. (D) Skin thickness was measured after H\&E staining. (E) EAU was induced in WT $(n=9)$ and TIPE2-deficient $(n=10)$ mice as described in the Materials and Methods. Twenty-one days after immunization, H\&E staining of the eye section was performed. Data were combined from two separate experiments. (F) Mice were treated as in (E) and EAU scores were determined on a scale of 0-4 based on the number, type, and size of lesions. (G) Total T cells were isolated from wild-type and TIPE2-deficient mice and adoptively transferred to Rag1-/- mice $\left(10 \times 10^{6} /\right.$ mouse). EAU was induced as described in the Materials and Methods and characterized as in $\mathbf{( F )}$. ${ }^{*} P<0.05 ;{ }^{\star \star} P<0.01$.
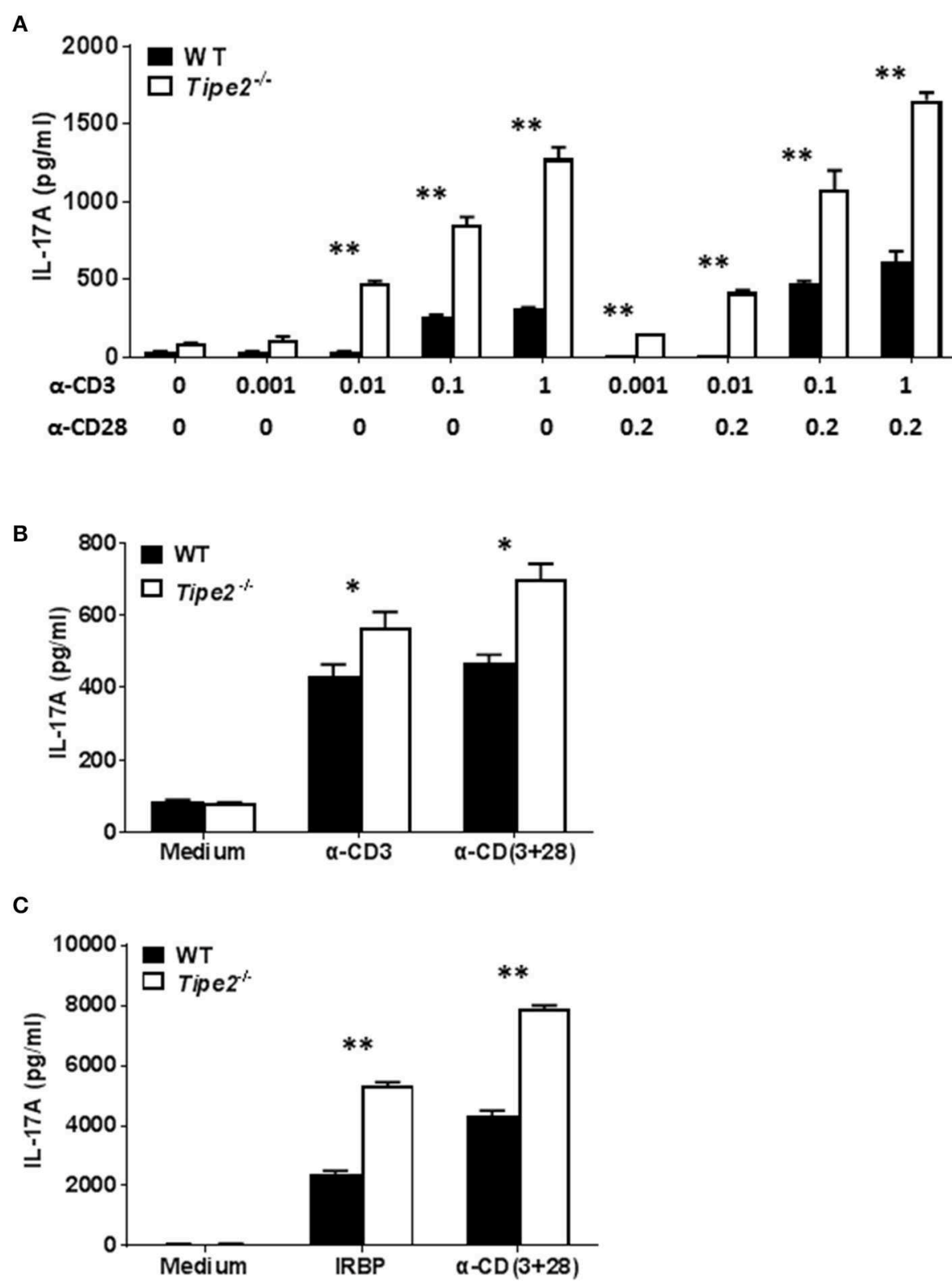

FIGURE 2 | TIPE2 suppresses IL-17A production by splenic T cells. (A) CD4 ${ }^{+}$T cells were isolated from untreated WT $(n=3)$ and TIPE2-deficient mice $(n=3)$ and cultured with or without different concentrations $(\mu \mathrm{g} / \mathrm{ml})$ of plate-bound anti-CD3 plus soluble anti-CD28 as indicated. After $48 \mathrm{~h}$, culture supernatants were collected and the concentration of IL-17A was determined by ELISA. Data are representative of three separate experiments. (B) WT $(n=5)$ and TIPE2-deficient $(n=5)$ mice were treated as in Figure 1A and killed 3 days after the first IMQ treatment. Total splenocytes were isolated and cultured at 1 million per well in 96-well plate with or without plate-bound anti-CD3 $(0.5 \mu \mathrm{g} / \mathrm{ml})$ or/and anti-CD28 $(0.5 \mu \mathrm{g} / \mathrm{ml})$. After $48 \mathrm{~h}$, the concentration of IL-17A in the culture supernatants was determined by ELISA. Data are representative of two separate experiments. (C) EAU was induced in WT $(n=4)$ and TIPE2-deficient $(n=5)$ mice as in Figure 1E and killed 21 days following immunization. Total splenocytes were isolated and cultured at 1 million per well in 96-well plate with or without IRBP $(30 \mu \mathrm{g} / \mathrm{ml})$ or anti-CD3 (0.5 $\mu \mathrm{g} / \mathrm{ml})$ plus anti-CD28 mAb $(0.5 \mu \mathrm{g} / \mathrm{ml})$. After $48 \mathrm{~h}$, the concentration of IL-17A in the culture supernatants was determined by ELISA. Data are representative of two separate experiments. ${ }^{\star} P<0.05 ;{ }^{\star *} P<0.01$. 
A

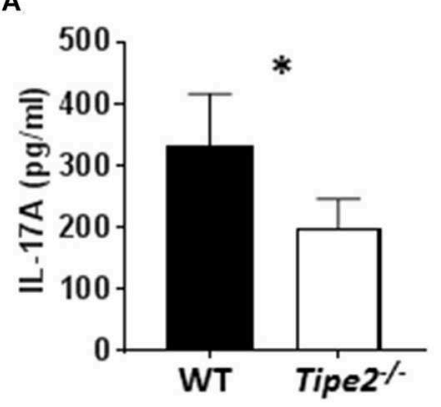

C

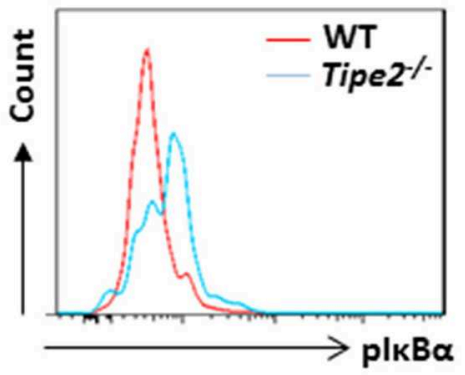

B

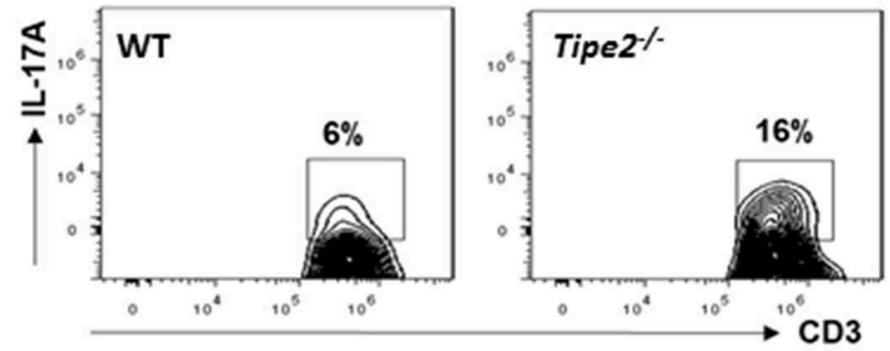

D

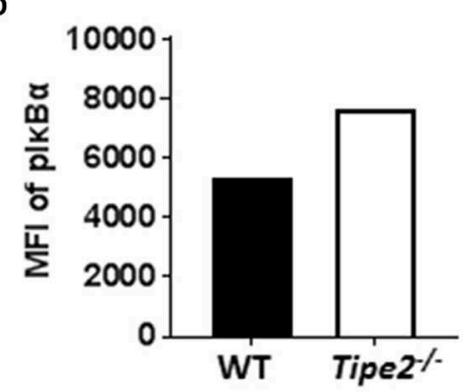

F

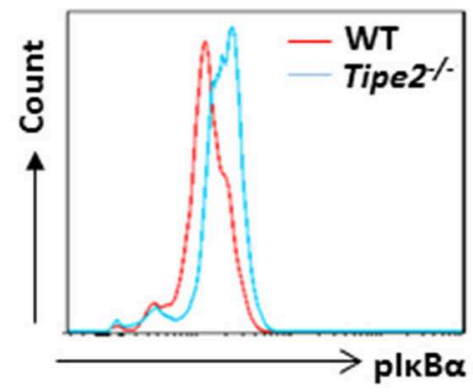

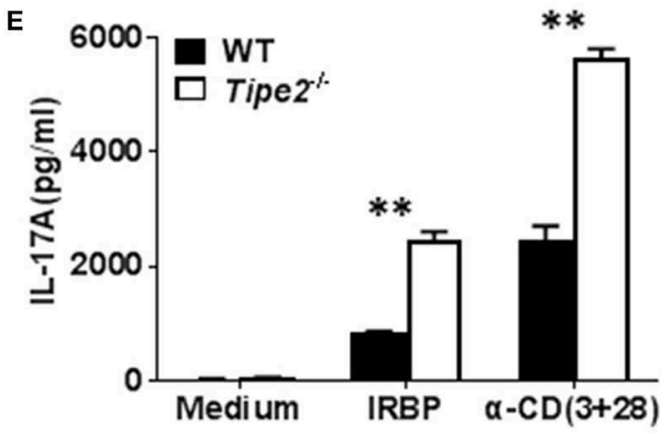

H

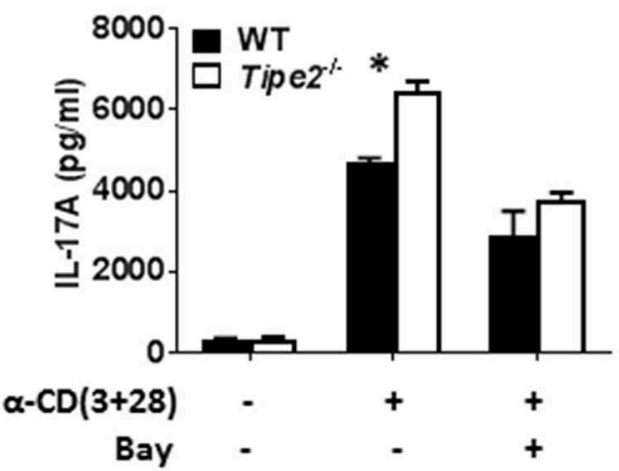

FIGURE 3 | The production of IL-17A is decreased in the skin but increased in the eye of TIPE2-deficient mice. (A-D) WT $(n=5)$ and TIPE2-deficient $(n=5)$ mice were treated as in Figure 1A and killed 3 days after the first IMQ treatment. (A) Tissue extracts were prepared from the back skin and the concentration of IL-17A in the tissue extract was determined by ELISA. (B) Total cells from the back skin were isolated and stimulated in vitro with PMA+ionomycin in the presence of GolgiStop 
FIGURE 3 | for $6 \mathrm{~h}$. Cells were first stained with anti-CD3, then fixed, permeabilized and stained with anti-IL-17A and examined by flow cytometry. Cells shown were gated on $\mathrm{CD}^{+} \mathrm{T}$ cells. (C) Total cells from the back skin were isolated and stained with anti-CD3. After fixation and permeabilization, cells were then stained with anti-phospho- $\mathrm{K}_{\mathrm{K}} \alpha$ antibody, followed by staining with DyLight ${ }^{\mathrm{TM}}$ 488-conjugated goat anti-mouse IgG. Stained cells were then examined by flow cytometry. Cells shown were gated on $\mathrm{CD}^{+} \mathrm{T}$ cells. (D) Relative expression level of phosphorylated $\mathbf{l}_{\boldsymbol{k}} \mathrm{B} \alpha$ was shown as the mean fluorescence intensity $(\mathrm{MFI})$. (E-H) WT ( $\left.n=4\right)$ and TIPE2-deficient $(n=5)$ mice were treated as in Figure 1E. Mice were killed 21 days after the immunization and total cells were isolated from the eye. (E) Cells were cultured with or without IRBP $(30 \mu \mathrm{g} / \mathrm{ml})$ or anti-CD3 $(0.5 \mu \mathrm{g} / \mathrm{ml})$ plus anti-CD28 mAb $(0.5 \mu \mathrm{g} / \mathrm{ml})$. After $48 \mathrm{~h}$, the concentration of IL-17A in the culture supernatants was determined by ELISA. (F) The level of phosphorylated $I_{\kappa} B \alpha$ was determined as in (C). (G) Relative expression level of phosphorylated lкB $\alpha$ was shown as the mean fluorescence intensity (MFI). (H) Cells were cultured with or without plate-bound anti-CD3 (0.5 $\mu \mathrm{g} / \mathrm{ml})$ plus soluble anti-CD28 (0.5 $\mu \mathrm{g} / \mathrm{ml})$. In addition, NF- $\kappa \mathrm{B}$ inhibitor BAY11-7082 (1 $\mu \mathrm{M})$ was used to inhibit NF- $\kappa$ B activity as indicated. After $48 \mathrm{~h}$, level of IL-17A in the supernatants was determined by ELISA. Data are representative of two separate experiments. ${ }^{*} P<0.05$; ${ }^{* \star} P<0.01$.

of TIPE2 in T cells in regular IMQ-induced psoriasis model and EAU model.

\section{TIPE2 Suppresses the Production of IL-17A by T Cells}

Both IMQ-induced psoriasis and EAU model contains a strong $\mathrm{T}$ cell component and the disease development is dependent on IL-17A. To determine the potential effect of TIPE2 deficiency on the production of IL-17A by $\mathrm{T}$ cells, we examined the expression of IL-17A produced by $\mathrm{T}$ cells in vitro. First we isolated $\mathrm{CD}^{+} \mathrm{T}$ cells from the spleen of untreated WT and TIPE2-deficient mice and cultured them in vitro with or without different concentrations of plate-bound anti-CD3 and soluble anti-CD28. We found that TIPE2 deficient $\mathrm{T}$ cells produced significantly higher level of IL-17A (Figure 2A). Secondly, we isolated total splenocyte from IMQ-treated WT and TIPE2deficient mice and cultured them in vitro with or without plate-bound anti-CD3 and/or soluble anti-CD28. We found that the expression of IL-17A was also significantly increased by TIPE2-deficient $\mathrm{T}$ cells (Figure 2B). Thirdly, we isolated total splenocyte from WT and TIPE2-deficient mice that have been treated to induce EAU. Cells were then cultured in vitro with or without IRBP or anti-CD3 plus anti-CD28. Again we found that TIPE2-deficient $\mathrm{T}$ cells produced significantly more IL-17A (Figure 2C). Taking together, these results indicate that TIPE2 is a negative regulator of IL-17A expression in $\mathrm{T}$ cells.

\section{The Production of IL-17A Is Decreased in the Skin but Increased in the Eye of TIPE2-Deficient Mice}

To investigate whether TIPE2 deficiency alters IL-17A production in the inflamed skin, tissue extracts were prepared from the skin of IMQ-treated WT and TIPE2-deficient mice and the production of IL-17A was measured by ELISA. We found that the production of IL-17A was significantly decreased in the skin from TIPE2-deficient mice (Figure 3A). This result is in consistency with the phenotype that TIPE2-deficiency alleviates IMQ-induced psoriasis. However, when flow cytometry was used to examine the percentage of IL-17-producing cells within gated $\mathrm{CD}^{+}{ }^{+} \mathrm{T}$ cells, we found that the percentage of IL-17A-producing cells was much higher in TIPE2-deficient mice (Figure 3B). In addition, we also found that the phosphorylation of Iкb $\alpha$ was significantly increased in TIPE2-deficient T cells (Figures 3C,D). Similar experiments were performed with the cells isolated from the inflamed eye of WT and TIPE2-deficient mice that have been treated to induce EAU. In consistency with the phenotype that TIPE2-deficiency promotes the development of EAU, the production of IL-17A (Figure 3E) and the phosphorylation of Iкb $\alpha$ (Figures 3F,G) was significantly increased by TIPE2deficient $\mathrm{T}$ cells. In addition, we also found that WT and TIPE2-deficient $\mathrm{T}$ cells no longer displayed difference in IL-17A expression after treatment with NF- $\kappa$ B inhibitor BAY11-7082 (Figure 3H). Taking together, these results indicate that TIPE2 may suppress IL-17A production by $\mathrm{T}$ cells through the inhibition of NF- $\kappa \mathrm{B}$ activation.

\section{The Percentage of T Cells in TIPE2-Deficient Mice Is Decreased in the Skin but Comparable in the Eye Compared With That in WT Mice}

Although TIPE2-deficient T cells produced more IL-17A, TIPE2deficient mice produced much less IL-17A in the skin and displayed reduced severity of IMQ-induced psoriasis. To solve this paradox, we examined the percentage and absolute number of T cells in IMQ-treated WT and TIPE2-deficient mice. The results showed that, while the percentage (Figure 4A) and absolute number (Figure 4B) of $\mathrm{CD}^{+} \mathrm{T}$ cells were significantly increased in the blood from TIPE2-deficient mice, they were significantly decreased in the skin. The percentage and absolute number of $\mathrm{CD}^{+} \mathrm{T}$ cells were comparable in the draining lymph node (inguinal lymph node, ILN) between WT and TIPE2-deficient mice (Figures 4A,B). Because we have shown that TIPE2 suppresses IL-17A production by $\mathrm{T}$ cells during the development of IMQ-induced psoriasis (Figure 2B), the percentage (Figure 4C) and absolute number (Figure 4D) of $\mathrm{CD}^{+}{ }^{+} \mathrm{IL}-17 \mathrm{~A}^{+} \mathrm{T}$ cells was significantly increased in the blood and ILN as expected. However, the percentage and absolute number of $\mathrm{CD}^{+}{ }^{+} \mathrm{IL}-17 \mathrm{~A}^{+} \mathrm{T}$ cells was significantly decreased in the skin (Figures 4C,D). We think that this is due to the decreased percentage and number of $\mathrm{CD}^{+} \mathrm{T}$ cells found in the skin from TIPE2-deficient mice, despite the fact that the proportion of IL-17-producing cells within gated $\mathrm{CD}^{+}{ }^{+} \mathrm{T}$ cells was much higher in the skin from TIPE2-deficient mice (Figure 3B). This may also explain why the net production of IL-17A was significantly decreased in the skin from TIPE2deficient mice (Figure 3A). As for the EAU model, no significant difference was found in the inflamed eye as well as in the blood and draining lymph node (cervical lymph node, CLN) between WT and TIPE2-deficient mice in the percentage and absolute 
A

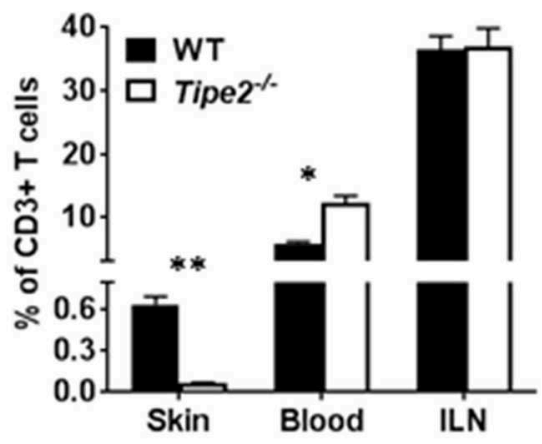

C

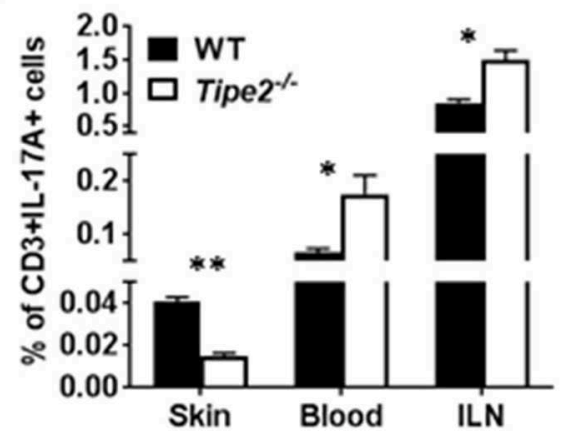

E

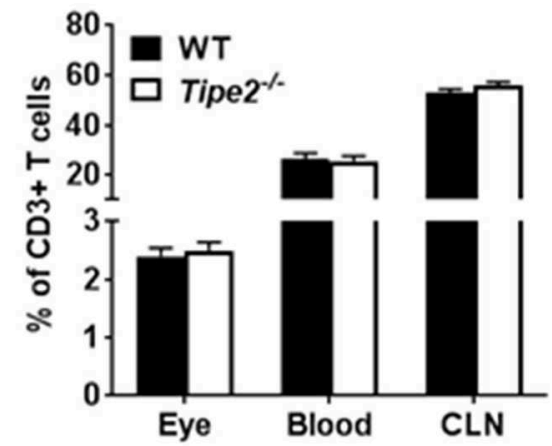

G

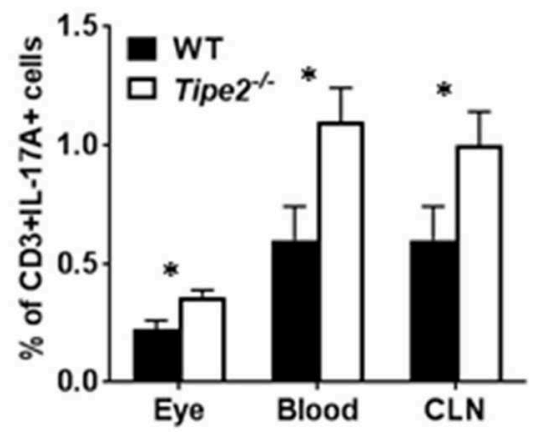

B

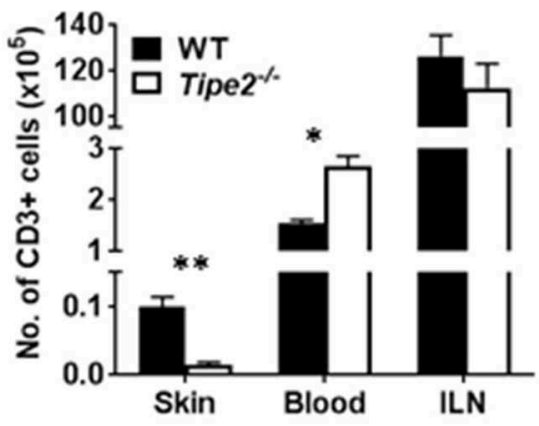

D

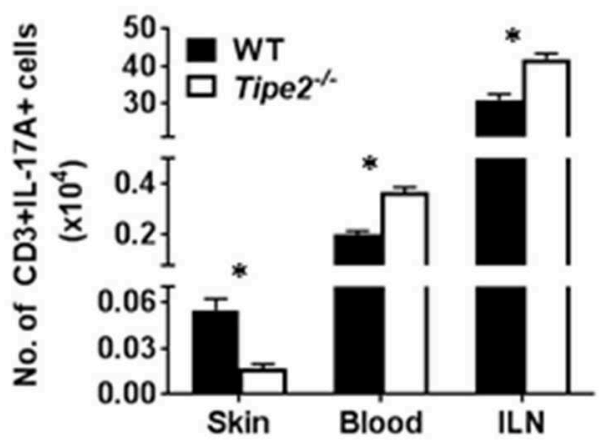

F

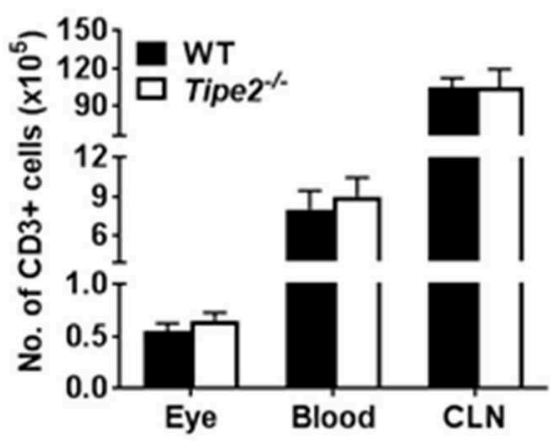

H

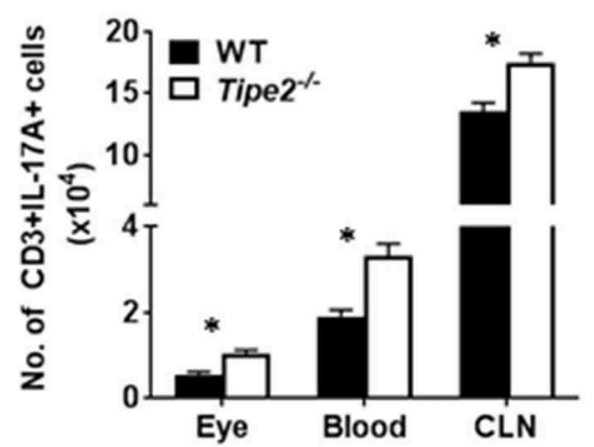

FIGURE 4 | Comparison of the percentage and absolute number of CD3 ${ }^{+}$and CD3 ${ }^{+} \mid \mathrm{L}-17 \mathrm{~A}^{+} \mathrm{T}$ cells in WT and TIPE2-deficient mice. (A-D) WT ( $n=5$ ) and TIPE2-deficient $(n=5)$ mice were treated as in Figure 1A and killed 3 days after the first IMQ treatment. The percentage (A) and absolute number (B) of CD3 ${ }^{+} \mathrm{T}$ cells in the skin $\left(0.8 \mathrm{~cm}^{2}\right)$, blood $(0.6 \mathrm{ml})$ and ILN were determined by cell surface staining with fluorescent labeled antibody against CD3. The percentage (C) and number 
FIGURE 4 | (D) of $\mathrm{CD}^{+} \mathrm{IL}-17 \mathrm{~A}^{+} \mathrm{T}$ cells in the skin $\left(0.8 \mathrm{~cm}^{2}\right)$, blood $(0.6 \mathrm{ml})$ and ILN was determined by cell surface staining as described above followed by intracellular staining with fluorescent labeled antibody against IL-17A. $(\mathbf{E}-\mathbf{H}) \mathrm{WT}(n=6)$ and TIPE2-deficient $(n=7)$ mice were treated as in Figure 1E. Mice were killed 21 days after the immunization and the percentage and number of $\mathrm{CD}^{+} \mathbf{( E , F )}$ and $\mathrm{CD}^{+}{ }^{+} \mathrm{IL}-17 \mathrm{~A}^{+} \mathrm{T}$ cells $\mathbf{( G , H )}$ in the eye (one eye), blood $(0.6 \mathrm{ml})$ and $\mathrm{CLN}$ were determined as described above. ILN, inguinal lymph node; CLN, cervical lymph node. ${ }^{*} P<0.05 ;{ }^{\star *} P<0.01$.

number of $\mathrm{CD}^{+} \mathrm{T}$ cells (Figures 4E,F). However, because we have shown that TIPE2 suppresses IL-17A production by $\mathrm{T}$ cells during the development of EAU (Figure 2C), the percentage and absolute number of $\mathrm{CD}^{+}{ }^{+} \mathrm{IL}-17 \mathrm{~A}^{+} \mathrm{T}$ cells was significantly increased in the eye as well as in the blood and CLN from TIPE2deficient mice (Figures 4G,H). Taken together, these results indicate that, although TIPE2-deficient T cells produced more IL$17 \mathrm{~A}$ in both disease models, they are defective in migration to the skin in IMQ-induced psoriasis model but not to the eye in EAU model. Next we focused on the roles of TIPE2 in regulating T cell migration during the development of IMQ-induced psoriasis.

\section{T Cells From IMQ-Treated TIPE2-Deficient Mice Express Normal Levels of Chemokine Receptors but Are Defective in Chemotaxis in vitro}

During the development of psoriasis, mature activated $\mathrm{T}$ cells migrate through the postcapillary venules into the dermis after establishing molecular interactions mediated by tissue selective integrins and chemokine receptors (homing receptors). To determine how TIPE2 affects $\mathrm{T}$ cell migration during the development of psoriasis, we examined the expression of multiple chemokine receptors on the surface of $\mathrm{CD}^{+} \mathrm{T}$ cells from the ILN and blood of IMQ-treated WT and TIPE2-deficient mice. Our results showed that the there is no significant difference in the expression of CXCR3, CXCR4, CCR4, CCR5, CCR6, CCR7, and CCR9 between IMQ-treated WT and TIPE2-deficient mice (Figures 5A,B). However, in vitro chemotaxis assay showed that TIPE2-deficient $\mathrm{T}$ cells from ILN were defective in migration toward IP10 and CCL19 (Figure 5C), which are the ligand for CCR7 and CXCR3, respectively. Similar results were found with the cells from the blood of IMQ-treated mice (Figure 5D). In order to exclude the possibility that decreased local chemokine production led to the defective migration of TIPE2-deficient $\mathrm{T}$ cells to the skin, we also examined the expression of multiple chemokines in the skin. Our results revealed that the mRNA expression of most of the chemokines was not decreased but even increased in the skin from TIPE2-deficient mice (Figure 5E). Because most of those chemokines were direct targets of NF- $\mathrm{kB}$, it is possible that TIPE2 suppresses the production of chemokine in the skin through the inhibition of NF- $\mathrm{KB}$ activity.

\section{T Cells From IMQ-Treated TIPE2-Deficient Mice Are Defective in Leading-Edge Formation During Chemotaxis}

Previous studies have shown that TIPE2 promotes leading-edge formation in neutrophils through enhancing phosphoinositidedependent signaling and cytoskeleton remodeling. Therefore, we examined the polarization of F-action and phosphor-AKT
(T308) in $\mathrm{CD}^{+} \mathrm{T}$ cells isolated from the ILN of IMQ-treated WT and TIPE2-deficient mice in response to point-source stimulation with IP10. Our results demonstrated that, although the distribution of F-actin and phosphor-AKT was aggregated on the surface of both WT and TIPE2-deficient T cells, more TIPE2deficient $\mathrm{T}$ cells were not polarized (Figures $6 \mathrm{~A}, \mathrm{~B}$ ). Interestingly, the total amount of F-actin and phosphor-AKT were increased in TIPE2-deficient $\mathrm{T}$ cells (Figure 6C). Taking together, these results indicate that, although TIPE2 suppresses the expression of F-actin and phosphor-AKT, it promotes the leading-edge formation during chemotaxis and consequently enhances $\mathrm{T}$ cell directional migration.

\section{DISCUSSION}

Although it has been reported that TIPE2 is a negative immune regulator, the exact role of TIPE2 during the development of autoimmune disease remains elusive. Contradictory results have been reported when investigating the role of TIPE2 during the development of different types of autoimmune diseases. Using IMQ-induced psoriasis model and EAU model, our current study revealed that TIPE2 may either promote or suppress autoimmunity, depending on the specific inflammatory microenvironment in different types of autoimmune diseases.

Since TIPE2 functions as a negative regulator of adaptive immune response, we speculate that TIPE2-deficient mice will be more susceptible to developing psoriasis and EAU. However, our current study showed that, while TIPE2-deficient mice develop more severe EAU, they unexpectedly develop less severe IMQ-induced psoriasis. In 2017, Fayngerts et al. reported that TIPE2 functioned as a local enhancer of cytoskeleton remodeling and promoted leading-edge formation in neutrophils (20). Our previous work also showed that TIPE2 enhances the cytoskeleton remodeling and promotes the thymus egress of tTregs (28). In the current study we further confirmed that TIPE2 may promote $\mathrm{T}$ cell migration via the same mechanism in the psoriasis model. This would explain why TIPE2-deficient mice develop less severe IMQ-induced psoriasis. We speculate that TIPE2 may play both anti-inflammatory and pro-inflammatory roles during the development of autoimmune diseases. Although $\mathrm{T}$ cells produced more IL-17A in both psoriasis and EAU model, they were defective in migration to the skin but not to the inflamed eye. The final outcome depends on the balance between these two opposing effects. This theory may also explain why the IMQ-induced skin inflammation of TIPE2-deficient mice is only marginally reduced compared with that of WT mice.

However, it still remains a question why TIPE2-deficient $\mathrm{T}$ cells were defective in migration to the site of inflammation in one particular autoimmune disease but not in another? After priming in the draining lymph node, mature activated 


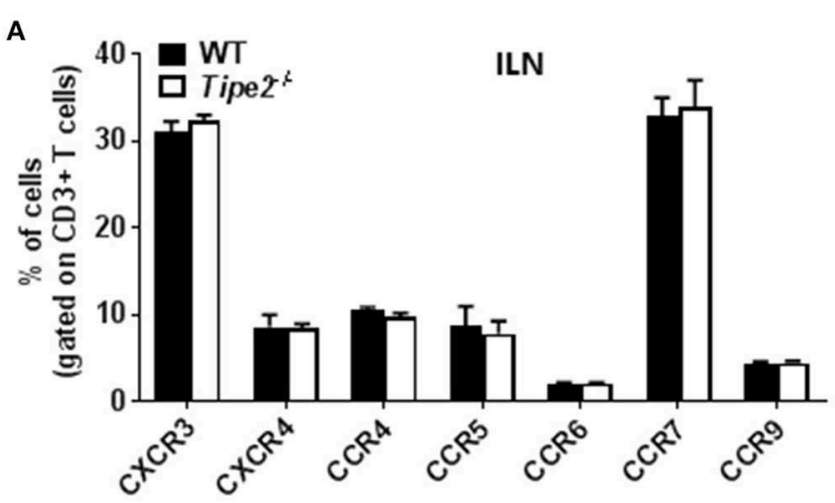

B

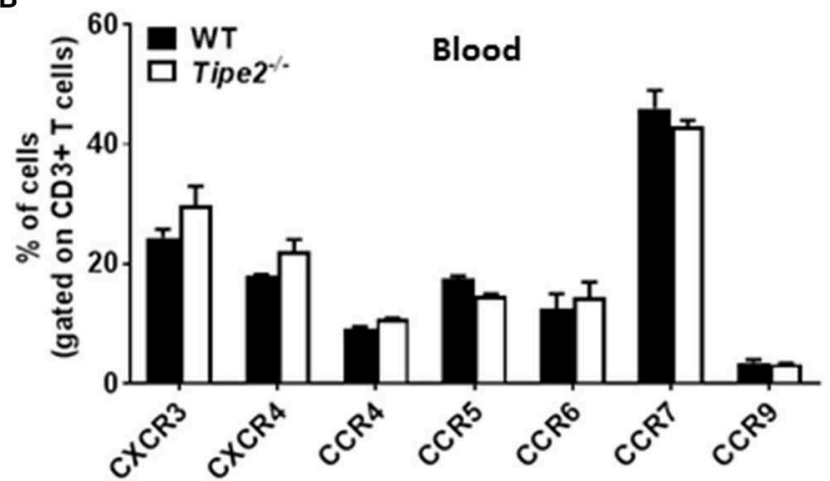

C
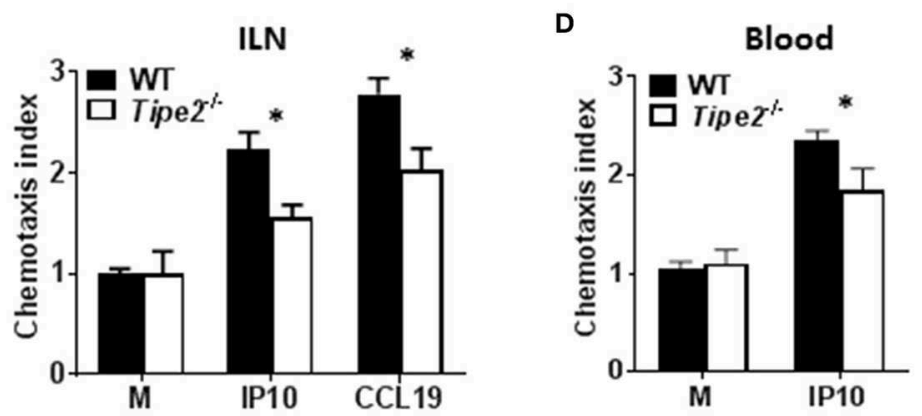

E

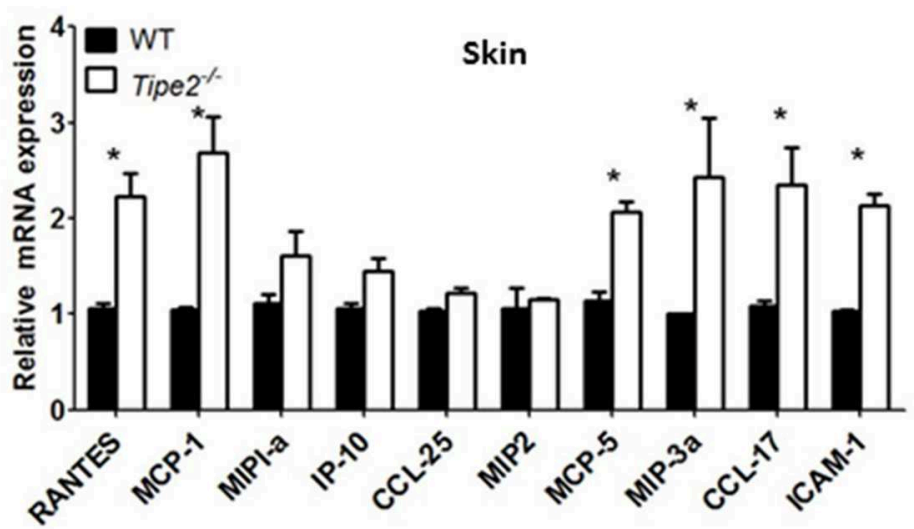

FIGURE 5 | T cells from TIPE2-deficient mice express normal levels of chemokine receptors but are defective in chemotaxis in vitro. WT ( $n=5$ ) and TIPE2-deficient ( $n$ $=5$ ) mice were treated as in Figure 1A and killed 3 days after the first IMQ treatment. (A) Total cells were isolated from ILN and the expression of indicated chemokine receptors on the surface of $\mathrm{CD}^{+} \mathrm{T}$ cells was determined by cell surface staining with florescence-labeled antibodies against CD3 and chemokine receptors. Data 
FIGURE 5 | shown are for gated CD3 ${ }^{+}$T cells. (B) Lymphocytes were isolated from blood and the expression of indicated chemokine receptors on the surface of $\mathrm{CD}^{+} \mathrm{T}$ cells was determined as in (A). Data shown are for gated CD3 ${ }^{+} \mathrm{T}$ cells. (C,D) Total T cells were isolated from ILN (C) and blood lymphocyte (D). in vitro transwell assay was performed to determine the migratory capacity of T cells toward IP10 and CCL19, which are the ligand for CXCR3 and CCR7, respectively. The chemotaxis index was calculated as mentioned in the Materials and Methods. (E) Total RNA was extracted from the back skin, and the mRNA expression of indicated chemokines was determined by quantitative RT-PCR. Data are representative of two separate experiments. ILN: inguinal lymph node. ${ }^{\star} P<0.05$.

A
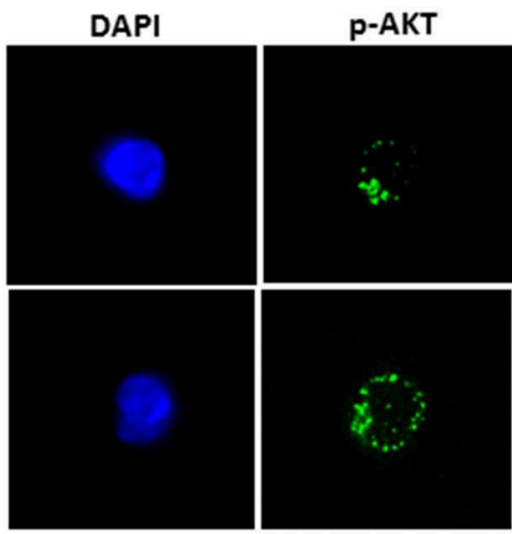

P-AKT

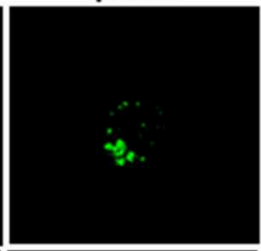

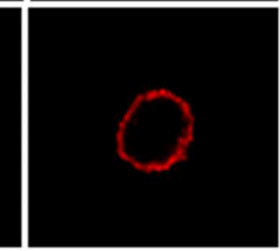

C

F-actin

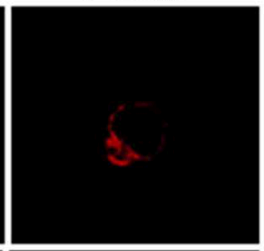

B

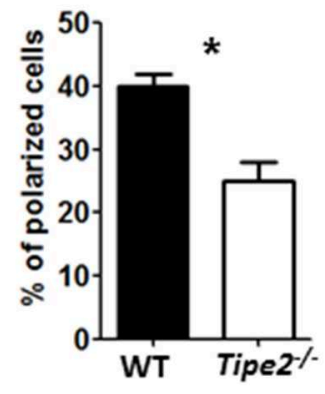

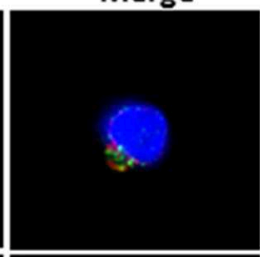
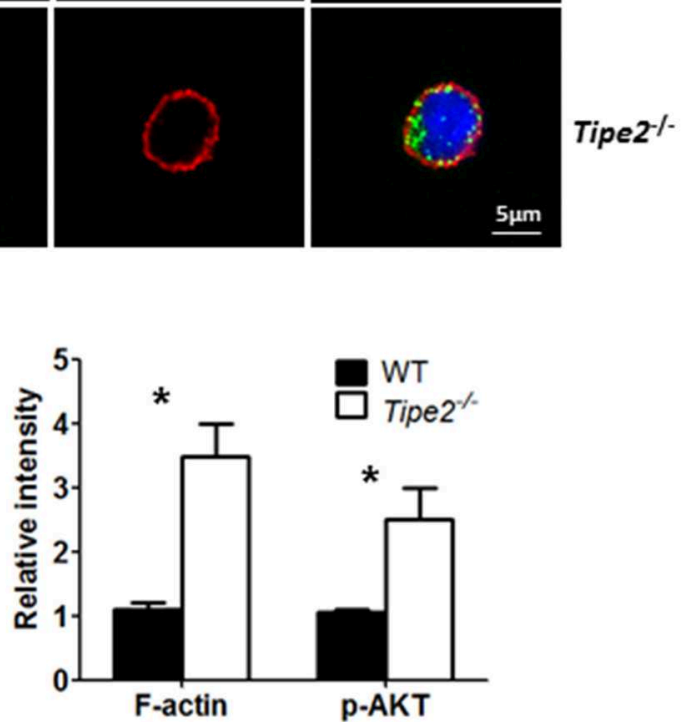

FIGURE 6 | TIPE2-deficient T cells are defective in leading-edge formation during chemotaxis. WT $(n=5)$ and TIPE2-deficient $(n=5)$ mice were treated as in Figure 1A and killed 3 days after the first IMQ treatment. Total T cells were isolated from inguinal lymph node and then subjected to point-source stimulation with IP10 at $1 \mu \mathrm{g} / \mathrm{ml}$ for $3 \mathrm{~min}$ at $37^{\circ} \mathrm{C}$ and stained with Phalloidin, anti-phospho-AKT antibody and DNA-binding dye DAPI. (A) The distributions of F-actin, phospho-AKT and DAPI in WT and TIPE2-deficient T cells were assessed by confocal microscopy. Data are representative of two separate experiments. (B) The percentages of polarized WT and TIPE2-deficient T cells were calculated. (C) The total intensity of F-actin and p-AKT was calculated using ImageJ. For (B,C), data are pooled results from two separate experiments with more than 50 cells analyzed per genotype. ${ }^{\star} P<0.05$.

Ag-specific $\mathrm{T}$ cells migrate through the postcapillary venules into local inflammatory site through a chemotaxis-dependent manner (29). Alternatively, primed T cells may also traffick to local inflammatory site through random migration. For example, random migration contributes to cytotoxicity of activated $\mathrm{CD} 8^{+}$ T-cells and may be used as a biomarker to predict the effect of immunotherapy using activated lymphocytes (30). Thus, depending on the specific inflammatory microenviroment in different types of autoimmune disease, TIPE2-deficiency may or may not affect the accumulation of $\mathrm{T}$ cells in the local inflammatory site. In EAU model, because pro-inflammatory leads to the breakdown of RBB (Retinal-Blood-Barrier), the majority of $\mathrm{T}$ cells that accumulated in the flamed eye may migrate in a chemotaxis-independent manner. The total amount of F-actin was increased in TIPE2-deficient $\mathrm{T}$ cells further indicates that TIPE2 in T cells may suppress non-directional cell movement.
While EAU in animals was used as a model of human uveitis, treating mice with innate TLR7/8 ligand IMQ rapidly induces dermatitis closely resembling human psoriasis. They are both T-cell mediated autoimmune diseases animal model, because only $\mathrm{T}$ cells can adoptively transfer those diseases $(11,14)$. Studies in these two disease models demonstrated that Th17 rather than Th1 cells play a critical role during their pathogenesis $(10,11)$. Because IL-17A is the primary Th17 cell effector cytokine, disease development was almost completely blocked in mice deficient for IL-17A or IL-17 receptor $(31,32)$. In vivo neutralization of IL-17A is able to ameliorate EAU and IMQ-induced psoriasis (12-14). While nuclear hormone receptor $\mathrm{ROR} \gamma \mathrm{T}$ is a master regulator of the differentiation of IL-17-producing $\mathrm{T}$ cells (33), other factors such as STAT3 and NF- $\mathrm{KB}$ have also been shown to regulate the expression of IL-17A $(34,35)$. TIPE2 negatively regulates immune response through inhibiting the activity of NF- $\mathrm{KB}$ 
in $\mathrm{T}$ cells (36). Our results also showed that the level of phosphorylated I $\mathrm{I} \mathrm{B} \alpha$ was markedly up-regulated in TIPE2deficient $\mathrm{T}$ cells derived from the inflamed eye and skin. Furthermore, we showed that WT and TIPE2-deficient T cells no longer displayed difference in IL-17A expression after treatment with NF- $\kappa$ B inhibitor. These results suggest that TIPE2 may inhibit the expression of IL-17A in T cells by suppressing NF$\kappa \mathrm{B}$ activity.

In addition to Th17 cells, IL-17A is also produced by a variety of cell types from the innate and adaptive immune systems $(37,38)$. Other types of T cells such as CD8 T cells, NKT cells and Gamma delta $(\gamma \delta)$ T cells are also significant potential sources of IL-17A (38-40). In our current study, we didn't distinguish the $\mathrm{T}$ cell types in which TIPE2 inhibits the expression of IL17A. While one group reported that Th17 cells are the major source of IL-17A in psoriatic dermis (41), others showed that the majority of IL-17A in the skin was produced by IL-23-responsive dermal $\gamma \delta \mathrm{T}$ cells $(40,42)$. Thus, future study is needed to determine the role of TIPE2 on IL-17A production in different IL-17A-producing T cells.

In summary, our study has revealed that TIPE2 can function as both a negative and positive regulator of autoimmunity. On one hand, TIPE2 could suppress inflammatory response through the inhibition of IL-17A production by $\mathrm{T}$ cells. On the other hand, TIPE2 could promote inflammatory response through enhancing the directional migration of $\mathrm{T}$ cells. The final outcome may depend on the balance of TIPE2 mediated anti-inflammatory and pro-inflammatory effects.

\section{REFERENCES}

1. Nomura I, Gao B, Boguniewicz M, Darst MA, Travers JB, Leung DY. Distinct patterns of gene expression in the skin lesions of atopic dermatitis and psoriasis: a gene microarray analysis. J Allergy Clin Immunol. (2003) 112:1195-202. doi: 10.1016/j.jaci.2003.08.049

2. Harden JL, Krueger JG, Bowcock AM. The immunogenetics of psoriasis: a comprehensive review. J Autoimmun. (2015) 64:66-73. doi: 10.1016/j.jaut.2015.07.008

3. Ausubel FM. Short Protocols in Molecular Biology: A Compendium of Methods From Current Protocols In Molecular Biology. New York, NY: Greene Pub. Associates; Wiley-Interscience (1989)

4. Fierlbeck G, Rassner G. Treatment of psoriasis and psoriatic arthritis with interferon gamma. J Invest Dermatol. (1990) 95(6 Suppl):138s-41s. doi: 10.1111/1523-1747.ep12875040

5. Mee JB, Cork MJ, di Giovine FS, Duff GW, Groves RW. Interleukin1: a key inflammatory mediator in psoriasis? Cytokine. (2006) 33:72-8. doi: 10.1016/j.cyto.2005.12.001

6. Stenderup K, Rosada C, Worsaae A, Dagnaes-Hansen F, Steiniche T, Hasselager E, et al. Interleukin-20 plays a critical role in maintenance and development of psoriasis in the human xenograft transplantation model. $\mathrm{Br}$ J Dermatol. (2009) 160:284-96. doi: 10.1111/j.1365-2133.2008.08890.x

7. Tonel G, Conrad C. Interplay between keratinocytes and immune cells-recent insights into psoriasis pathogenesis. Int J Biochem Cell Biol. (2009) 41:963-8. doi: 10.1016/j.biocel.2008.10.022

8. Ali FR, Warren RB. Psoriasis and susceptibility to other autoimmune diseases: an outline for the clinician. Expert Rev Clin Immunol. (2013) 9:99-101. doi: 10.1586/eci.12.94

9. Walsh SR, Shear NH. Psoriasis and the new biologic agents: interrupting a T-AP dance. CMAJ. (2004) 170:1933-41. doi: 10.1503/cmaj.1031335

\section{DATA AVAILABILITY STATEMENT}

All datasets generated for this study are included in the manuscript/supplementary files.

\section{ETHICS STATEMENT}

This study was carried out in accordance with the recommendations of the Animal Care and Use Committee of Shenzhen Institutes of Advanced Technology, Chinese Academy of Sciences. The protocol was approved by Shenzhen Institutes of Advanced Technology, Chinese Academy of Sciences.

\section{AUTHOR CONTRIBUTIONS}

$\mathrm{QR}$ and TW designed research and analyzed data. RL, XH, and WG performed research. QR wrote the manuscript.

\section{FUNDING}

This study was supported by the National Natural Science Foundation of China (81530027); Shenzhen Science and Technology Innovation Commission (JCYJ20170413165432016).

\section{ACKNOWLEDGMENTS}

The authors thank Dr. Suxia Liu from Shangdong University, P. R. China for kindly providing the TIPE2 deficient mice.

10. Luger D, Silver PB, Tang J, Cua D, Chen Z, Iwakura Y, et al. Either a Th17 or a Th1 effector response can drive autoimmunity: conditions of disease induction affect dominant effector category. J Exp Med. (2008) 205:799-810. doi: $10.1084 /$ jem.20071258

11. Raychaudhuri SP. Role of IL-17 in psoriasis and psoriatic arthritis. Clin Rev Allergy Immunol. (2013) 44:183-93. doi: 10.1007/s12016-0128307-1

12. Zou W, Wu Z, Xiang X, Sun S, Zhang J. The expression and significance of $\mathrm{T}$ helper cell subsets and regulatory $\mathrm{T}$ cells $\mathrm{CD}(4)(+) \mathrm{CD}(2)(5)(+)$ in peripheral blood of patients with human leukocyte antigen B27-positive acute anterior uveitis. Graefes Arch Clin Exp Ophthalmol. (2014) 252:665-72. doi: 10.1007/s00417-014-2567-9

13. Giuliari GP, Sadaka A, Hinkle DM. Biologic agents in experimental autoimmune uveitis. Int Ophthalmol. (2014) 34:145-56. doi: 10.1007/s10792-013-9756-0

14. Martin DA, Towne JE, Kricorian G, Klekotka P, Gudjonsson JE, Krueger JG, et al. The emerging role of IL-17 in the pathogenesis of psoriasis: preclinical and clinical findings. J Invest Dermatol. (2013) 133:17-26. doi: 10.1038/jid.2012.194

15. Sun H, Gong S, Carmody RJ, Hilliard A, Li L, Sun J, et al. TIPE2, a negative regulator of innate and adaptive immunity that maintains immune homeostasis. Cell. (2008) 133:415-26. doi: 10.1016/j.cell.2008. 03.026

16. Li D, Song L, Fan Y, Li X, Li Y, Chen J, et al. Down-regulation of TIPE2 mRNA expression in peripheral blood mononuclear cells from patients with systemic lupus erythematosus. Clin Immunol. (2009) 133:422-7. doi: 10.1016/j.clim.2009.08.014

17. Li F, Zhu X, Yang Y, Huang L, Xu J. TIPE2 alleviates systemic lupus erythematosus through regulating macrophage polarization. Cell Physiol Biochem. (2016) 38:330-9. doi: 10.1159/000438633 
18. Shi GS, et al. The expression of TIPE2 in patients with rheumatoid arthritis and its effect to NF-кB pathway. China J Modern Med. (2014) doi: 10.3969/j.issn.1005-8982.2014.04.008

19. Lou Y, Sun H, Morrissey S, Porturas T, Liu S, Hua X, et al. Critical roles of TIPE2 protein in murine experimental colitis. JImmunol. (2014) 193:1064-70. doi: 10.4049/jimmunol.1400415

20. Fayngerts SA, Wang Z, Zamani A, Sun H, Boggs AE, Porturas TP, et al. Direction of leukocyte polarization and migration by the phosphoinositidetransfer protein TIPE2. Nat Immunol. (2017) 18:ni.3866. doi: 10.1038/ ni.3866

21. Fan T, Wang S, Yu L, Yi H, Liu R, Geng W, et al. Treating psoriasis by targeting its susceptibility gene Rel. Clin Immunol. (2016) 165:47-54. doi: 10.1016/j.clim.2016.03.009

22. van de Kerkhof PC. The Psoriasis Area and Severity Index and alternative approaches for the assessment of severity: persisting areas of confusion. $\mathrm{Br}$ J Dermatol. (1997) 137:661-2. doi: 10.1111/j.1365-2133.1997.tb03819.x

23. Bae SH, Yun SJ, Lee JB, Kim SJ, Won YH, Lee SC. Algorithm to select optimal systemic anti-psoriatic drugs in relation with patients' Psoriasis Area and Severity Index score for plaque psoriasis. J Dermatol. (2016) 43:643-9. doi: 10.1111/1346-8138.13195

24. Grajewski RS, Silver PB, Agarwal RK, Su SB, Chan CC, Liou GI, et al. Endogenous IRBP can be dispensable for generation of natural CD4 ${ }^{+} \mathrm{CD} 25^{+}$ regulatory $\mathrm{T}$ cells that protect from IRBP-induced retinal autoimmunity. J Exp Med. (2006) 203:851-6. doi: 10.1084/jem.20050429

25. Chan CC, Caspi RR, Ni M, Leake WC, Wiggert B, Chader GJ, et al. Pathology of experimental autoimmune uveoretinitis in mice. J Autoimmun. (1990) 3:247-55. doi: 10.1016/0896-8411(90)90144-H

26. Fischer FR, Santambrogio L, Luo Y, Berman MA, Hancock WW, Dorf ME. Modulation of experimental autoimmune encephalomyelitis: effect of altered peptide ligand on chemokine and chemokine receptor expression. J Neuroimmunol. (2000) 110:195-208. doi: 10.1016/S0165-5728(00) 00351-9

27. Xiaomei L. Interleukin-17 (IL-17)-induced microRNA 873 (miR873) contributes to the pathogenesis of experimental autoimmune encephalomyelitis by targeting A20 ubiquitin-editing enzyme. J Biol Chem. (2014) 289:28971-86. doi: 10.1074/jbc.M114.577429

28. Fan T, Huang X, Liu C, Liu R, Wang T, Ruan Q. Egress of murine regulatory T cells from the thymus requires TIPE2. Biochem Biophys Res Commun. (2018) 500:376-83. doi: 10.1016/j.bbrc.2018.04.082

29. Masopust D, Schenkel JM. The integration of T cell migration, differentiation and function. Nat Rev Immunol. (2013) 13:309-20. doi: 10.1038/nri 3442

30. Onishi H, Kiyota A, Koya N, Tanaka H, Umebayashi M, Katano M, et al. Random migration contributes to cytotoxicity of activated $\mathrm{CD} 8^{+} \mathrm{T}$ lymphocytes but not NK cells. Anticancer Res. (2014) 34:3947-56.

31. Nakajima K, Kanda T, Takaishi M, Shiga T, Miyoshi K, Nakajima $\mathrm{H}$, et al. Distinct roles of IL-23 and IL-17 in the development of psoriasis-like lesions in a mouse model. J Immunol. (2011) 186:4481-9. doi: 10.4049/jimmunol.1000148

32. van der Fits L, Mourits S, Voerman JS, Kant M, Boon L, Laman JD, et al. Imiquimod-induced psoriasis-like skin inflammation in miceis mediated via the IL-23/IL-17 axis. J Immunol. (2009) 182:5836-45. doi: 10.4049/jimmunol.0802999

33. Ivanov II, McKenzie BS, Zhou L, Tadokoro CE, Lepelley A, Lafaille JJ, et al. The orphan nuclear receptor RORgammat directs the differentiation program of proinflammatory IL-17 ${ }^{+}$T helper cells. Cell. (2006) 126:1121-33. doi: 10.1016/j.cell.2006.07.035

34. Kim KW, Cho ML, Park MK, Yoon CH, Park SH, Lee SH, et al. Increased interleukin-17 production via a phosphoinositide 3-kinase/Akt and nuclear factor kappaB-dependent pathway in patients with rheumatoid arthritis. Arthritis Res Ther. (2005) 7:R139-48. doi: 10.1186/ar1470

35. Rubino SJ, Geddes K, Girardin SE. Innate IL-17 and IL-22 responses to enteric bacterial pathogens. Trends Immunol. (2012) 33:112-8. doi: 10.1016/j.it.2012.01.003

36. Shi C, Zhang S, Hong S, Pang J, Yesibulati Y, Yin P, et al. The pro-apoptotic effects of TIPE2 on AA rat fibroblast-like synoviocytes via regulation of the DR5-caspase-NF-кB pathway in vitro. Oncotargets Therapy. (2016) 9:9931000. doi: 10.2147/OTT.S92907

37. Albanesi C, Scarponi C, Cavani A, Federici M, Nasorri F, Girolomoni G. Interleukin-17 is produced by both Th1 and Th2 lymphocytes, and modulates interferon-gamma- and interleukin-4-induced activation of human keratinocytes. J Invest Dermatol. (2000) 115:81-7. doi: 10.1046/j.1523-1747.2000.00041.x

38. Monteiro M, Almeida CF, Agua-Doce A, Graca L. Induced IL-17-producing invariant NKT cells require activation in presence of TGF-beta and IL-1beta. J Immunol. (2013) 190:805-11. doi: 10.4049/jimmunol.1201010

39. Ortega C, Fernández-AS, Carrillo JM, Romero P, Molina IJ, Moreno JC, et al. IL-17-producing CD8 ${ }^{+} \mathrm{T}$ lymphocytes from psoriasis skin plaques are cytotoxic effector cells that secrete Th17-related cytokines. J Leukoc Biol. (2009) 86:435-43. doi: 10.1189/JLB.0109046

40. Cai Y, Shen X, Ding C, Qi C, Li K, Li X, et al. Pivotal role of dermal IL17-producing gammadelta $\mathrm{T}$ cells in skin inflammation. Immunity. (2011) 35:596-610. doi: 10.1016/j.immuni.2011.08.001

41. Lynde CW, Poulin Y, Vender R, Bourcier M, Khalil S. Interleukin 17A: toward a new understanding of psoriasis pathogenesis. J Am Acad Dermatol. (2014) 71:141-50. doi: 10.1016/j.jaad.2013.12.036

42. Ramirez-Valle F, Gray EE, Cyster JG. Inflammation induces dermal Vgamma4+ gammadeltaT17 memory-like cells that travel to distant skin and accelerate secondary IL-17-driven responses. Proc Natl Acad Sci USA. (2015) 112:8046-51. doi: 10.1073/pnas.1508990112

Conflict of Interest: The authors declare that the research was conducted in the absence of any commercial or financial relationships that could be construed as a potential conflict of interest.

Copyright (c) $2019 \mathrm{Liu}, \mathrm{He}$, Geng, Wang and Ruan. This is an open-access article distributed under the terms of the Creative Commons Attribution License (CC BY). The use, distribution or reproduction in other forums is permitted, provided the original author(s) and the copyright owner(s) are credited and that the original publication in this journal is cited, in accordance with accepted academic practice. No use, distribution or reproduction is permitted which does not comply with these terms. 